Pacific Journal of Mathematics

THE REVERSING RESULT FOR THE JONES POLYNOMIAL AND KENNETH MU L RT 


\title{
THE REVERSING RESULT FOR THE JONES POLYNOMIAL
}

\author{
W. B. R. LICKORISH AND K. C. MilletT
}

\begin{abstract}
A short proof is given, using linear skein theory, of the theorem of V.F.R. Jones that the one variable "Jones" polynomial associated to an oriented link is independent of the choice of strand orientations, up to a multiple of the variable.
\end{abstract}

The Jones polynomial of an oriented link $K$ is the element $V(K)$ of $\mathbf{Z}\left[t^{ \pm 1 / 2}\right]$ defined by

$$
\begin{gathered}
t V\left(K_{+}\right)-t^{-1} V\left(K_{-}\right)+\left(t^{1 / 2}-t^{-1 / 2}\right) V\left(K_{0}\right)=0 \\
V(U)=1,
\end{gathered}
$$

where $U$ is the unknot and $K_{+}, K_{-}$, and $K_{0}$ are oriented links identical except in a small ball where they have positive, negative and null crossings respectively. Details are to be found in [J], [F-Y-H-L-M-O] or [L-M]. This note gives a short proof of the following theorem of V. F. R. Jones which states, inter alia, that, up to multiplication by a unit of $\mathbf{Z}\left[t^{ \pm 1 / 2}\right], V(K)$ is independent of the orientation of $K$. The original proof used the theory of braids and plaits; the proof here is a simple induction together with a neat illustration of linear skein theory. The proof fails (as it must) for the general two-variable oriented link polynomial only at the start of the induction.

TheOREM ( $V . F . R$. Jones). Suppose that a component $\gamma$ of an oriented link $K$ has linking number $\lambda$ with the union of the other components. Let $\hat{K}$ be $K$ with the direction of $\gamma$ reversed. Then $t^{3 \lambda} V(K)=V(\hat{K})$.

Proof. The proof is in five sections.

(1) The theorem is true for the two links of Figure 1. This is an easy exercise in computation.

(2) It is well known that if the orientation of every component of $K$ is reversed then $V(K)$ is unchanged. Further, $V\left(K_{1} \# K_{2}\right)=V\left(K_{1}\right) V\left(K_{2}\right)$ where $K_{1} \# K_{2}$ is any connected sum of oriented links $K_{1}$ and $K_{2}$, and also $V(\bar{K})=\overline{V(K)}$ where $\bar{K}$ is the obverse (reflection) of $K$ and $\overline{f(t)}=$ $f\left(t^{-1}\right)$. Thus if the Theorem is true for $K_{1}$ and $K_{2}$ it is true for $\bar{K}_{1}$ and for $K_{1} \# K_{2}$. 

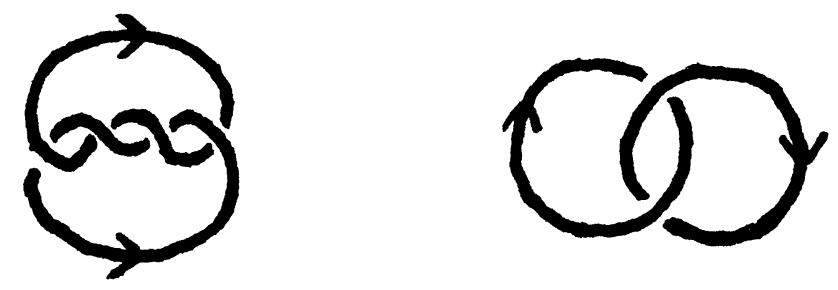

FiguRE 1

(3) Consider the self-crossings of the component $\gamma$ in some presentation of $K$. Induction (as repeatedly used in section three of [L-M]) on the number of these crossings and on the number of them that have to be switched to unknot $\gamma$ shows that $\gamma$ may be assumed to be unknotted.

(4) Let the unknotted component $\gamma$ bound a disc that meets the remainder of $K$ in $n$ points. Proceed by induction on $n$. The start of the induction will be given in (5); for the moment assume that $n \geq 4$. Figure 2 depicts a skein triple in which $K$ is $K_{0}$. The disc bounded by $\gamma$ is shown meeting the remainder of $K$ in $n$ points shown as crosses. In $K_{-}, \gamma$ has become two unlinked curves $\gamma_{1}^{-}$and $\gamma_{2}^{-}$that bound discs that meet the remainder of $K_{-}$in $n_{1}$ and $n_{2}$ points and that link the remainder of $K$ with linking numbers $\lambda_{1}$ and $\lambda_{2}$ respectively. The situation of $K_{+}$is exactly similar except that $\gamma_{1}^{+}$and $\gamma_{2}^{+}$are linked as shown.
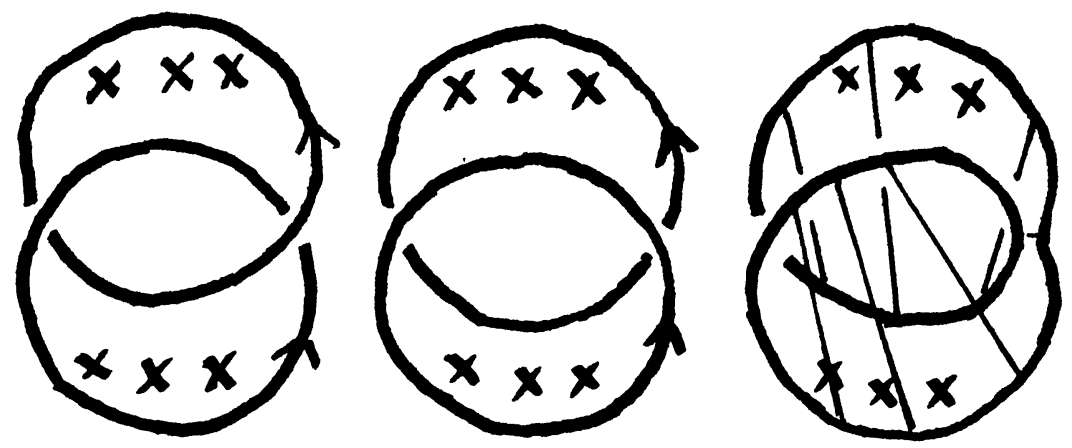

Figure 2

Thus $n_{1}+n_{2}=n$ and $\lambda_{1}+\lambda_{2}=\lambda$. Choose $n_{1}$ and $n_{2}$ so that each is at most $n-2$ (recall $n \geq 4$ ). Let $\hat{K}_{+}, \hat{K}_{-}$, and $\hat{K}_{0}$ be the same links but with the $\gamma_{l}^{ \pm}$and $\gamma$ all reversed. Then

$$
\begin{aligned}
& t V\left(K_{+}\right)-t^{-1} V\left(K_{-}\right)+\left(t^{1 / 2}-t^{-1 / 2}\right) V\left(K_{0}\right)=0 \\
& t V\left(\hat{K}_{+}\right)-t^{-1} V\left(\hat{K}_{-}\right)+\left(t^{1 / 2}-t^{-1 / 2}\right) V\left(\hat{K}_{0}\right)=0 .
\end{aligned}
$$

But, by the induction on $n$, reversing $\gamma_{1}$ and then $\gamma_{2}^{-}$gives

$$
t^{3 \lambda_{2}} t^{3 \lambda_{1}} V\left(K_{-}\right)=V\left(\hat{K}_{1}\right)
$$


and reversing $\gamma_{1}^{+}$and then $\gamma_{2}^{+}$gives

$$
t^{3\left(\lambda_{2}-1\right)} t^{3\left(\lambda_{1}+1\right)} V\left(K_{+}\right)=V\left(\hat{K}_{+}\right) .
$$

It follows immediately that $t^{3 \lambda} V(K)=V(\hat{K})$.

This argument extends a little further when $n=3$. If $\lambda$ is also 3, choose $n_{1}=1$ and $n_{2}=2$, then the above argument holds if the theorem is known for $n=3$ and $\lambda=1$ and for $n \geq 2$. Similarly when $n=3$, $\lambda=-3$.

(5) Suppose that $n=3$ and $\lambda= \pm 1$. It is required to show that whatevery tangle is inserted into the room (the rectangle) of Figure 3 to give $K$, the Theorem holds true and $t^{3} V(K)=V(\hat{K})$. However, the module over $Z\left[t^{ \pm 1 / 2}\right]$ of the linearised skein of this room is generated by the six inhabitants shown in Figure 4.

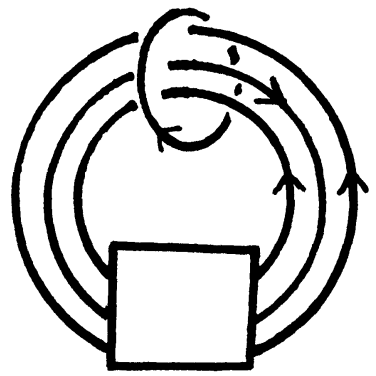

Figure 3
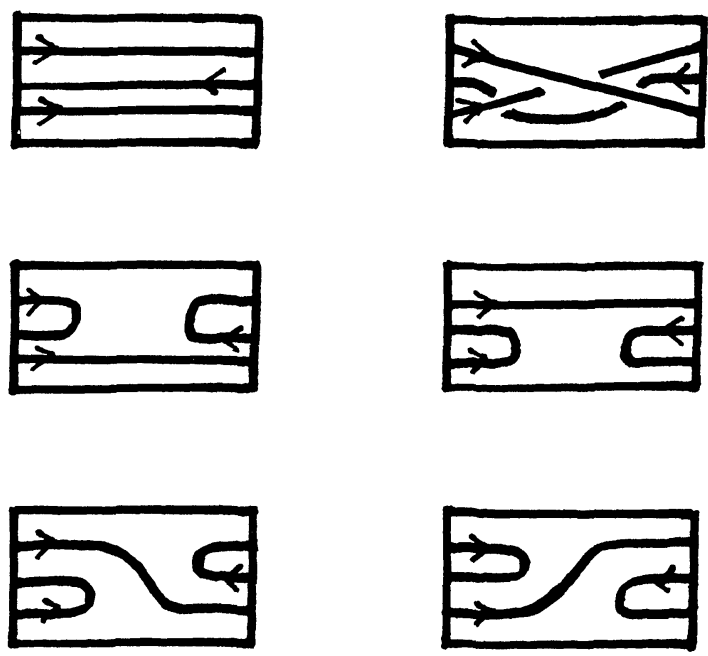

Figure 4 
Thus all that is required is to check that whichever of these generators is inserted into the room to give $K$ the theorem holds. This follows at once from (1) and (2). A simplified version of this proof works when $n=2$ there then being only two generators of the analogous rooms (see [L-M]). The case $n=1$ is immediate from (1) and (2) and $n=0$ is trivial.

This completes the proof; only step (1) fails to generalise to the general (two-variable) link polynomial.

\section{REFERENCES}

[F-Y-H-L-M-O] P. Freyd, D. Yetter, J. Hoste, W. B. R. Lickorish, K. Millett, and A. Ocneanu, $A$ new polynomial invariant of knots and links, Bull. Amer. Math. Soc., 12 (2) (1985), 239-246.

[G] C. Giller, $A$ family of links and the Conway calculus, Trans. Amer. Math. Soc., 270 (1982), 75-109.

[J] V. F. R. Jones, A polynomial invariant for knots via von Neumann algebras, Bull. Amer. Math. Soc., 12 (1) (1985), 103-111.

[L-M] W. B. R. Lickorish and K. C. Millett, A polynomial invariant of oriented links, (to appear).

Received March 25, 1985.

Department of Pure Mathematics

16, Mill LANE

CAMBRIDGe, CB2 1SB

ENGLAND

AND

UNIVERSITY OF CALIFORNIA

SANTA BARBARA, CA 93106, U.S.A. 


\section{PACIFIC JOURNAL OF MATHEMATICS EDITORS}

\author{
V. S. VARADARAJAN \\ (Managing Editor) \\ University of California \\ Los Angeles, CA 90024 \\ HeRbert Clemens \\ University of Utah \\ Salt Lake City, UT 84112 \\ R. FINN \\ Stanford University \\ Stanford, CA 94305
}

HERMANN FLASCHKA

University of Arizona

Tucson, AZ 85721

RAMESH A. GANGOLLI

University of Washington

Seattle, WA 98195

VAUGHAN F. R. JONES

University of California

Berkeley, CA 94720

ROBION KIRBY

University of California

Berkeley, CA 94720
C. C. MOORE

University of California

Berkeley, CA 94720

H. SAMELSON

Stanford University

Stanford, CA 94305

HAROLD STARK

University of California, San Diego

La Jolla, CA 92093

\section{ASSOCIATE EDITORS}
R. Arens
E. F. BECKENBACH
B. H. NEUMANN
F. WOLF
K. YoshIDA (1906-1982)

\section{SUPPORTING INSTITUTIONS}

UNIVERSITY OF ARIZONA

UNIVERSITY OF BRITISH COLUMBIA

CALIFORNIA INSTITUTE OF TECHNOLOGY

UNIVERSITY OF CALIFORNIA

MONTANA STATE UNIVERSITY

UNIVERSITY OF NEVADA, RENO

NEW MEXICO STATE UNIVERSITY

OREGON STATE UNIVERSITY
UNIVERSITY OF OREGON

UNIVERSITY OF SOUTHERN CALIFORNIA

TANFORD UNIVERSITY

UNIVERSITY OF HAWAII

UNIVERSITY OF TOKYO

UNIVERSITY OF UTAH

WASHINGTON STATE UNIVERSITY

UNIVERSITY OF WASHINGTON 


\section{Pacific Journal of Mathematics}

Vol. 124, No. $1 \quad$ May, 1986

Kinetsu Abe and Martin Andrew Magid, Relative nullity foliations and indefinite isometric immersions

Erik P. van den Ban, A convexity theorem for semisimple symmetric

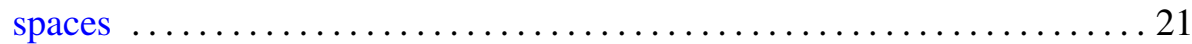

Bo Berndtsson and Thomas Joseph Ransford, Analytic multifunctions, the $\bar{\partial}$-equation, and a proof of the corona theorem .................. 57

Brian Boe and David H. Collingwood, Intertwining operators between

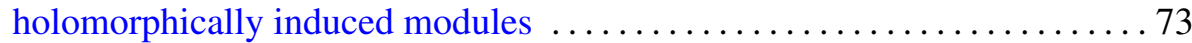

Giuseppe Ceresa and Alessandro Verra, The Abel-Jacobi isomorphism for

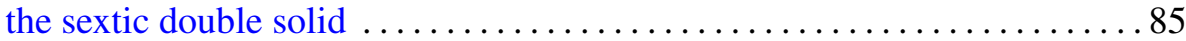

Kun Soo Chang, Jae Moon Ahn and Joo Sup Chang, An evaluation of the conditional Yeh-Wiener integral ........................... 107

Charles Dale Frohman, Minimal surfaces and Heegaard splittings of the

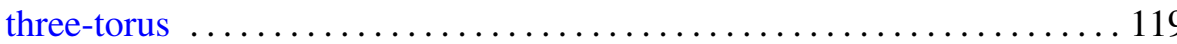

Robert M. Guralnick, Power cancellation of modules $\ldots \ldots \ldots \ldots \ldots \ldots 131$

Kenneth Hardy and Kenneth S. Williams, On the solvability of the Diophantine equation $d V^{2}-2 e V W-d W^{2}=1 \ldots \ldots \ldots \ldots \ldots \ldots \ldots \ldots \ldots$

Ray Alden Kunze and Stephen Scheinberg, Alternative algebras having

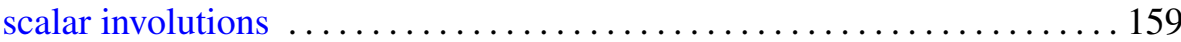

W. B. Raymond Lickorish and Kenneth Millett, The reversing result for the Jones polynomial $\ldots \ldots \ldots \ldots \ldots \ldots \ldots \ldots \ldots$

Guido Lupacciolu, A theorem on holomorphic extension of CR-functions

William Schumacher Massey and Lorenzo Traldi, On a conjecture of K. Murasugi

Dinakar Ramakrishnan, Spectral decomposition of $L^{2}(N \backslash \mathrm{GL}(2), \eta)$

Steven L. Sperber, On solutions of differential equations which satisfy certain algebraic relations 